\title{
Cultivar Identification, Pedigree Verification, and Diversity Analysis among Peach Cultivars Based on Simple Sequence Repeat Markers
}

\author{
Viji Sitther ${ }^{1}$ \\ Department of Biology, Morgan State University, Carnegie G64, 1700 E. Cold Spring Lane, \\ Baltimore, MD 21251 \\ Dapeng Zhang \\ Research Geneticist, Sustainable Perennial Crops Laboratory, Plant Science Institute, USDA-ARS, \\ Beltsville Agricultural Research Center, 10300 Baltimore Avenue, Bldg 001, Room 223, Beltsville, \\ MD 20705
}

\author{
Sadanand A. Dhekney \\ Assistant Professor, Department of Plant Sciences, University of Wyoming, Sheridan Research and \\ Extension Center, 663 Wyarno Road, Sheridan, WY 82801 \\ Donna L. Harris \\ 126-B Stallworth Agricultural Research Station, Fort Valley State University, 1005 State University \\ Drive, Fort Valley, GA 31030-4313
}

\author{
Anand K. Yadav \\ Director of Biotechnology and Graduate Programs, Fort Valley State University, 1005 State \\ University Drive, Fort Valley, GA 31030-4313 \\ William R. Okie \\ USDA-ARS, Southeastern Fruit and Tree Nut Research Laboratory, Room 104/127, 21 Dunbar Road, \\ Byron, GA 31008
}

\begin{abstract}
AdDitional INDEX wORDs. fingerprinting, genetic variation, inbreeding, molecular markers, parent-sibship analysis
ABstRaCt. Information on genetic relationships and pedigree structure in germplasm collections is vital to breeders in crop improvement programs. In this study, we assessed genetic identity, kinship distance, and parentage-sibship relationships among 37 peach (Prunus persica) accessions and breeding lines using simple sequence repeat (SSR) markers. Pairwise comparisons based on multilocus SSR profiles led to the identification of two synonymous groups including five accessions. Two pairs of parent-offspring and one full sibling relationships were identified using the likelihood method, and Bayesian cluster analysis partitioned the accessions into groups that were partially compatible with the known pedigree, origin, and flesh color. The 37 accessions were grouped into four clusters, which were largely supported by the known pedigree and origin of these accessions. Although the observed mean heterozygosity was 0.219, mean inbreeding coefficient was $\mathbf{0 . 6 3 5}$, indicating a high degree of inbreeding among the accessions. Eleven of the 15 SSR markers $(73.3 \%)$ tested were transferable to nine related Prunus species. Results of the study demonstrate that these SSRs could facilitate the assessment of genetic identity and pedigree structure.
\end{abstract}

Genetic improvement of peach, a diploid plant species $(2 \mathrm{n}=$ 16), has resulted in the development of a large number of cultivars (Fideghelli et al., 1998; Okie, 1998). Cultivars are classified into non-melting, clingstone types in which the flesh adheres to the stone, making it difficult to separate, or melting, mostly freestone types in which the flesh easily separates from the stone. Non-melting-type cultivars are preferred to melting types in some countries as a result of higher quality and firmness, which improves shippability and shelf life. In the United States, non-melting types are used for canning as well as for the early-

Received for publication 30 Aug. 2011. Accepted for publication 13 Feb. 2012. We thank Bryan Blackburn of USDA-ARS, SEFTNR, for assistance with sample collection. Support provided by the Fort Valley State University Agricultural Research Station is acknowledged.

${ }^{1}$ Corresponding author. E-mail: viji.sitther@morgan.edu. season shipping market (Brovelli et al., 1998; Okie, 1998). Although the majority of peaches sold in the United States are yellow-fleshed, white-fleshed cultivars are being increasingly planted, and a few red-fleshed cultivars (with either yellow or white backgrounds) are available. Use of a limited number of parents in breeding programs has led to reduction in the genetic diversity of peach germplasm available for crop improvement (Byrne, 1999; Scorza et al., 1985; Scorza and Okie, 1990).

A thorough characterization of available germplasm is crucial in providing breeders with valuable information on selection of parents, which could broaden the genetic base of resulting populations. Among various methods used for identification of cultivars, DNA-based markers are routinely used for fingerprinting and detecting genetic polymorphisms. Of these, simple sequence repeat or microsatellite markers, which are tandem-repeat nucleotides, are valuable in genetic studies 
as a result of their codominant and multiallelic nature (Morgante and Olivieri, 1993). These markers are widely used in crop improvement and breeding programs because promising parents can be identified in a relatively short period of time compared with traditional methods (Powell et al., 1996; Ramakrishna et al., 1995). SSRs have widely been used for comparative genetic studies in the Rosaceae family (Aranzana et al., 2002, Downey and Iezzoni, 2000), including peach, in which pedigree analysis of cultivars with known or controversial parentage has been accomplished (Cipriani et al., 1999; Dirlewanger et al., 2002).

The U.S. Department of Agriculture, Agricultural Research Service, Southeastern Fruit and Tree Nut Research Laboratory in Byron, GA (SEFTNRL) has had an active peach breeding program for the past 45 years resulting in the release of over 40 improved cultivars. However, no studies have been conducted on the genetic relationship among accessions and breeding lines

Table 1. Origin, key agronomic characteristics, and parentage of Prunus persica accessions from the germplasm collection of USDA-ARS at Byron, GA, used to test genetic relationships based of simple sequence repeat markers.

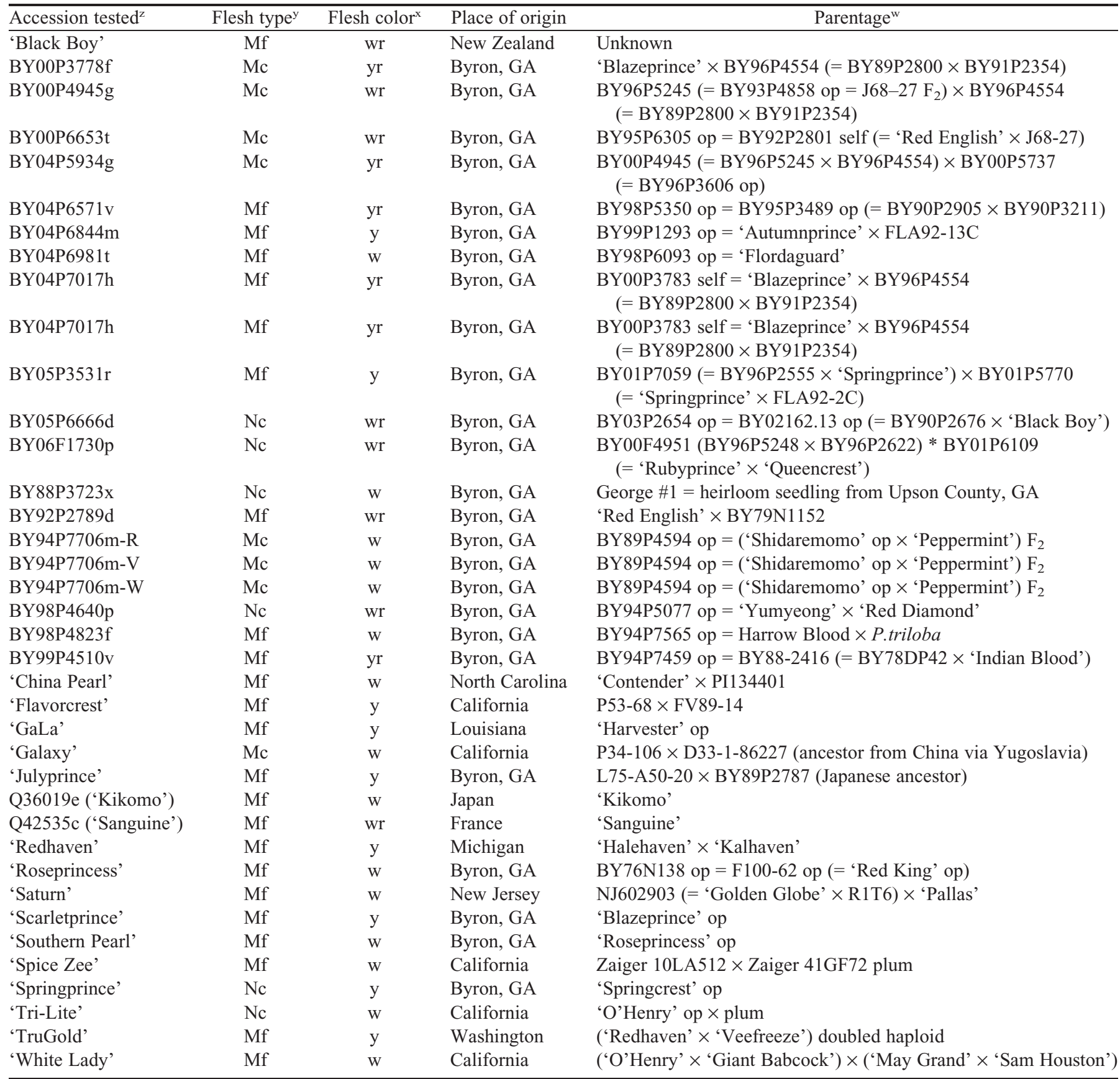

${ }^{\mathrm{z}}$ Accession BY04P7017h was included as duplicate sample. Accession BY94P7706m with varied flower colors; BY94P7706m-R = red; $\mathrm{BY} 94 \mathrm{P} 7706 \mathrm{~m}-\mathrm{V}=$ variegated; BY94P7706m-W = white.

${ }^{\mathrm{y}} \mathrm{M}=$ melting; $\mathrm{N}=$ non-melting; $\mathrm{c}=$ clingstone; $\mathrm{f}=$ freestone.

${ }^{\mathrm{x}} \mathrm{r}=$ red; $\mathrm{w}=$ white; $\mathrm{y}=$ yellow.

${ }^{\mathrm{w}}$ Additional information on parentage is indicated in parenthesis; self = self-pollinated; op = open-pollinated. 
used in genetic improvement. The objectives of the present study were to characterize genetic diversity among peach accessions with varying morphological traits, test parent-offspring and sibling relationships, and assess cross-transportability of SSR markers across related Prunus species.

\section{Materials and Methods}

Plant material. Thirty-seven peach accessions from the SEFTNRL collection were tested in this study (Table 1). In addition, 22 accessions from related Prunus species that included representative samples of apricot $(P$. armeniaca), bush cherry $(P$. japonica), european plum $(P$. domestica), japanese plum $(P$. salicina), myrobalan plum $(P$. cerasifera) and japanese plum $\times$ bush cherry, japanese plum $\times$ apricot, and peach $\times$ japanese plum hybrids were tested for cross-transferability (Table 2).

Leaf samples were obtained from the accessions at SEFTNRL. Actively growing shoot and leaf samples from spring flush of trees were harvested, bagged, labeled, and immediately frozen to $-80^{\circ} \mathrm{C}$. Samples were later ground to a fine powder in liquid nitrogen and stored at $-80{ }^{\circ} \mathrm{C}$.

DNA isolation AND QUANTIFiCATion. Total genomic DNA was isolated from $500 \mathrm{mg}$ of leaf tissue using a DNeasy Plant Maxi Kit (Qiagen, Valencia, CA). Samples were placed in a tissue lyser (Qiagen) for $2 \mathrm{~min}$ at $30 \mathrm{~Hz}$ before DNA extraction. Quality of DNA was checked on a $1 \%(\mathrm{w} / \mathrm{v})$ agarose gel and its concentration determined using a spectrophotometer (NanoDrop, Wilmington, DE). A portion of the DNA was diluted to $10 \mathrm{ng} \cdot \mu \mathrm{L}^{-1}$ in molecular grade water and stored at $-20{ }^{\circ} \mathrm{C}$.

Polymerase CHAIN REACTION AMPLIFICATION AND MICROSATELLITE IDENTIFICATION. A selected set of 15 SSR primers cloned and sequenced by Cipriani et al. (1999) and Testolin

Table 2. Accessions from related Prunus species and hybrids tested for cross-transferability of peach simple sequence repeats. ${ }^{\mathrm{z}}$

\begin{tabular}{|c|c|c|c|}
\hline Prunus species & Name & Accession tested & Place of origin \\
\hline \multirow[t]{3}{*}{ P. armeniaca } & Apricot & BY01c363t & Byron, GA \\
\hline & Apricot & BY91c003g & Byron, GA \\
\hline & Apricot & BY96c339m & Byron, GA \\
\hline \multirow[t]{2}{*}{ P. domestica } & European plum & 'Kubansky Legend' & Russia \\
\hline & European plum & 'Kubansky Karlik’ & Russia \\
\hline \multirow[t]{3}{*}{ P. salicinia ${ }^{\mathrm{y}}$} & Japanese plum & 'Mariposa' & California \\
\hline & Japanese plum & 'Robusto' & Byron, GA \\
\hline & Japanese plum & 'Morris' & Texas \\
\hline \multirow[t]{2}{*}{ P. cerasifera } & Myrobalan plum & 'Korean Wild' & Korea \\
\hline & Myrobalan plum & 'Clark Hill' & GA \\
\hline \multirow[t]{6}{*}{ P. salicinia ${ }^{\mathrm{y}} \times$ armeniaca } & Plumcot & 'Spring Satin' & Byron, GA \\
\hline & Plumcot & BY92z1389he & Byron, GA \\
\hline & Plumcot & BY92z1389hl & Byron, GA \\
\hline & Pluot & 'Flavor Gem' & California \\
\hline & Pluot & 'Flavor Rich' & California \\
\hline & Pluot & 'Flavor Grenade' & California \\
\hline \multirow[t]{2}{*}{$P$. persica $\times P$. salicinia ${ }^{\mathrm{y}}$} & Peach $\times$ japanese plum & BY94-2678s & Byron, GA \\
\hline & Peach $\times$ japanese plum & BY99-1125f & Byron, GA \\
\hline \multirow[t]{2}{*}{ P. salicinia ${ }^{\mathrm{y}} \times P$. japonica } & Japanese plum $\times$ cherry & BY96-1757e & Byron, GA \\
\hline & Japanese plum $\times$ cherry & NURI & Byron, GA \\
\hline \multirow{2}{*}{ P. japonica } & Bush cherry & 'Prag' & Oregon \\
\hline & Bush cherry & P. japonica $B$ & California \\
\hline
\end{tabular}

${ }^{\mathrm{z}}$ Accessions developed at USDA-ARS, Fruit and Tree Nut Research Laboratory, Byron, GA, or obtained from different geographic origins and grown at Byron, GA, were used.

${ }^{\mathrm{y}}$ Labeled as $P$. salicinia for simplicity but is a complex hybrid of the species with other plums. et al. (2000) was used in this study (Table 3). These markers have been demonstrated as useful in distinguishing peach genotypes. Polymerase chain reaction (PCR) amplifications were performed using WellRED fluorescent dye-labeled primers (Beckman Coulter, Fullerton, CA). Reactions were carried out in $25-\mu \mathrm{L}$ volume containing $10 \mathrm{ng}$ genomic DNA, $0.4 \mu \mathrm{M}$ dNTPs, $0.1 \mu \mathrm{M}$ fluorescent-labeled forward and reverse primers, $3.0 \mathrm{~mm} \mathrm{MgCl}_{2}$, and $0.1 \mathrm{U}$ Taq polymerase mixed in reaction buffer $(\mathrm{pH} 8.5)$. After an initial denaturation step of $5 \mathrm{~min}$ at $94{ }^{\circ} \mathrm{C}$, PCR amplifications were performed using an iCycler Version 1.259 system (Bio-Rad, Hercules, CA) under the following conditions: 50 cycles consisting of $94{ }^{\circ} \mathrm{C}$ for $45 \mathrm{~s}$, $57^{\circ} \mathrm{C}$ for $45 \mathrm{~s}$, and $72^{\circ} \mathrm{C}$ for $45 \mathrm{~s}$ with a final extension of $8 \mathrm{~min}$ at $72{ }^{\circ} \mathrm{C}$. The amplified loci were separated by capillary electrophoresis and analyzed on a $\mathrm{CEQ}^{\mathrm{TM}} 8000$ eight-channel capillary genetic analysis system (Beckman Coulter). Allele sizes were calculated to two decimal places by the $\mathrm{CEQ}^{\mathrm{TM}} 8000$ genetic analysis system. Allele calling was performed using the $\mathrm{CEQ}^{\mathrm{TM}} 8000$ binning wizard software (Version 7.0.55; Beckman Coulter) and manually examined.

Assessment of Genetic Diversity. Summary statistics for each SSR loci including mean number of alleles per locus, observed heterozygosity $\left(\mathrm{H}_{\mathrm{o}}\right)$, gene diversity, and inbreeding coefficient were computed using PowerMarker Version 3.0 (Liu and Muse, 2005). To assess the relationship among the accessions, pairwise genetic distance was computed using the distance procedure in GenAlEx 6 (Peakall and Smouse, 2006).

Cluster analysis was used to further examine the genetic relationship among accessions. Kinship coefficient among individual accessions $(n=37)$ was calculated using Microsatellite Analyzer (Dieringer and Schlötterer, 2002). A dendrogram was generated using the neighbor-joining algorithm (Saitou and Nei, 1987) available in PHYLIP (Felsenstein, 1989) and visualized using the TreeView Version 1.6.6 (Page, 1996).

Parentage ANd Sibship anAlysis. For cultivars with known parentage, the relationships were tested using parentage analysis. A likelihoodbased method implemented in the program CERVUS 3.0 was used for computation (Kalinowski et al., 2006; Marshall et al., 1998). For each parent-offspring match, the natural logarithm of the likelihood ratio (LOD) score was calculated. This score is the likelihood of maternity (or paternity) of a particular candidate parent relative to an arbitrary individual. The most probable parent of each offspring was identified on the basis of the critical difference in LOD scores $(\Delta)$ between the most likely and next most likely candidate parent. The assignment was set at a confidence of $95 \%$ and more.

To further examine the kinship and hidden sibling relationships among the peach accessions, the COLONY program (Jones and 
Table 3. Characteristics of 15 simple sequence repeat markers used for molecular polymorphism analysis of peach and related Prunus species.

\begin{tabular}{|c|c|c|c|}
\hline Primer & Repeat motif & Primer sequences $\left(5^{\prime}-3^{\prime}\right)$ & Allele range (no.) \\
\hline \multirow[t]{2}{*}{ UDP96-001 } & $(\mathrm{CA}) 17$ & AGTTTGATTTTCTGATGCATCC & $122-140$ \\
\hline & & TGCCATAAGGACCGGTATGT & \\
\hline \multirow[t]{2}{*}{ UDP96-003 } & $(\mathrm{CT}) 11(\mathrm{CA}) 28$ & TTGCTCAAAAGTGTCGTTGC & $124-144$ \\
\hline & & ACACGTAGTGCAACACTGGC & \\
\hline \multirow[t]{2}{*}{ UDP96-005 } & (AC)16TG(CT)2CA(CT)11 & GTAACGCTCGCTACCACAAA & $146-162$ \\
\hline & & CACCCAGCTCATACACCTCA & \\
\hline \multirow[t]{2}{*}{ UDP96-008 } & $(\mathrm{CA}) 23$ & TTGTACACACCCTCAGCCTG & $123-165$ \\
\hline & & TGCTGAGGTTCAGGTGAGTG & \\
\hline \multirow[t]{2}{*}{ UDP96-010 } & (GT)21(GAGT)4(GA)18 & CCCATGTGTGTCCACATCTC & $122-142$ \\
\hline & & TTGATGATTCCATGCGTCTC & \\
\hline \multirow[t]{2}{*}{ UDP96-013 } & (AG)22(TG)8TT(TG)10 & ATTCTTCACTACACGTGCACG & $184-208$ \\
\hline & & CCCCAGACATACTGTGGCTT & \\
\hline \multirow[t]{2}{*}{ UDP96-015 } & $(\mathrm{CA}) 31$ & CCTTGACCTATTTGTTCGTCA & $144-178$ \\
\hline & & ACTAGTCAAACAATCCCCCG & \\
\hline \multirow[t]{2}{*}{ UDP96-019 } & (TG)18(AG)7 & TTGGTCATGAGCTAAGAAAACA & $211-222$ \\
\hline & & TAGTGGCACAGAGCAACACC & \\
\hline \multirow[t]{2}{*}{ UDP97-401 } & (GA)19 & TAAGAGGATCATTTTTGCCTTG & $122-134$ \\
\hline & & CCCTGGAGGACTGAGGGT & \\
\hline \multirow[t]{2}{*}{ UDP97-402 } & $(\mathrm{AG}) 17$ & TCCCATAACCAAAAAAAACACC & $134-146$ \\
\hline & & TGGAGAAGGGTGGGTACTTG & \\
\hline \multirow[t]{2}{*}{ UDP97-403 } & $(\mathrm{AG}) 22$ & CTGGCTTACAACTCGCAAGC & $146-154$ \\
\hline & & CGTCGACCAACTGAGACTCA & \\
\hline \multirow[t]{2}{*}{ UDP98-405 } & $(\mathrm{AG}) 9$ & ACGTGATGAACTGACACCCA & $105-109$ \\
\hline & & GAGTCTTTGCTCTGCCATCC & \\
\hline \multirow[t]{2}{*}{ UDP98-407 } & (GA)29 & AGCGGCAGGCTAAATATCAA & $185-211$ \\
\hline & & AATCGCCGATCAAAGCAAC & \\
\hline \multirow[t]{2}{*}{ UDP98-408 } & $(\mathrm{CT}) 14$ & ACAGGCTTGTTGAGCATGTG & $102-104$ \\
\hline & & CCCTCGTGGGAAAATTTGA & \\
\hline \multirow{2}{*}{\multicolumn{2}{|c|}{ UDP98-411z (TC)16 }} & AAGCCATCCACTCAGCACTC & $134-160$ \\
\hline & & CCAAAAACCAAAACCAAAGG & \\
\hline
\end{tabular}

${ }^{\mathrm{z}}$ Sequence reported by Testolin et al. (2000). All other sequences were reported by Cipriani et al. (1999).

Wang, 2010) was used. Unlike the pairwise comparison that is used by CERVUS, COLONY uses a full-pedigree likelihood approach that allows the simultaneous inference of parentage and sibship. A model-based clustering algorithm implemented in the STRUCTURE software program (Pritchard et al., 2000) was applied to the SSR data to corroborate results from distancebased cluster analysis. The algorithm attempted to identify genetically distinct subpopulations based on allele frequencies. The number of clusters ( $K$ value, which indicated the number of subpopulations the program attempted to find) was set from two to 11 , and the analysis was carried out without assuming any prior information about the genetic group or geographic origin of the samples. Ten independent runs were assessed for each fixed number of clusters $(K)$. The $\Delta K$ value was computed to detect the most probable number of clusters (Evanno et al., 2005). Of the 10 independent runs, the one with the highest Ln $\operatorname{Pr}(X \mid K)$ value (log probability or log likelihood) was chosen and represented as bar plots.

IDENTIFICATION OF DUPLICATE AND VARIEGATED GENOTYPES. Pairwise multilocus comparisons were used to identify duplicates among the accessions based on SSR profiles. Accessions that matched at all the 15 loci tested were declared duplicates or synonymous accessions. Of particular interest was the identification of BY94P7706m with white (BY94P7706m-W), red (BY94P7706m-R), and variegated peppermint-type
(BY94P7706m-V) flowers in a single tree. In addition, one accession (BY04P7017h) was included as a duplicate sample. Statistical rigor was assessed for match declaration to determine whether two individuals may share the same multilocus genotype by chance (Waits et al., 2001). The computer program GenAlEx 6 (Peakall and Smouse, 2006) was used for genotype matching and computation of probability of identity (PID) among siblings (PID-sib).

Cross-species amplification. All 15 primers were evaluated for amplification on apricot, bush cherry, european plum, japanese plum $\times$ bush cherry, japanese plum, myrobalan plum, japanese plum $\times$ apricot, and peach $\times$ japanese plum hybrids (Table 2). Sample collection, DNA isolation, PCR amplification, and detection of SSR profiles were performed according to the procedure described previously.

\section{Results}

Microsatellite polymorphisms AND GENETIC Diversity. The 15 primers generated multiple alleles in the same size range as reported by Testolin et al. (2000) in the peach accessions. The 15 primers amplified a total of 80 different alleles with an average of 5.33 alleles per locus (Table 4). The SSR loci UDP98-407, UDP96-005, and UDP98-411 were most polymorphic producing eight alleles each. Allele scoring was repeatable for all microsatellite loci. Of the 570 amplification profiles scored in the study, $430(75.4 \%)$ were homozygous, whereas $140(24.6 \%)$ were heterozygous (data not shown). The mean expected heterozygosity among the 38 accessions was 0.54 and the observed heterozygosity was 0.22 . High inbreeding coefficient with an average of 0.62 was observed among the accessions. The only exception was with loci UDP96-019 in which inbreeding coefficient detected was low $(-0.03)$.

The 37 peach accessions grouped into six clusters based on kinship coefficient (Fig. 1). The clustering patterns presented a better representation of similarity relationships among cultivars that originated from various geographical regions and breeding lines developed at the research station. 'Southern Pearl', BY05P6666d, and BY04P6981t (which originated in Byron, GA) grouped together in Cluster I. The second cluster comprised of 'Spice Zee', 'Black Boy', and five other accessions, including the two descendants of 'Red English' (a generic term for red-fleshed local cultivars). 'White Lady', 'TruGold', and 'Roseprincess' (which originated in the United States) formed the third cluster. Q36019E (seedling of a Japanese ornamental peach), BY98P4640p (with a Korean parent), and the three pigment mutant clones of BY94P7706m (which have influence of Asian parentage) formed the fourth cluster. 
Table 4. Summary statistics for 37 peach accessions from the germplasm collection of USDA-ARS at Byron, GA, assessed with 15 simple sequence repeats.

\begin{tabular}{|c|c|c|c|c|c|c|}
\hline$\underline{\text { Locus }}$ & Alleles (no.) & $\begin{array}{c}\text { Effective } \\
\text { alleles (no.) }\end{array}$ & $\begin{array}{c}\text { Information } \\
\text { index (I) }\end{array}$ & $\begin{array}{c}\text { Observed } \\
\text { heterozygosity }\left(\mathrm{H}_{\mathrm{o}}\right)\end{array}$ & $\begin{array}{c}\text { Expected } \\
\text { heterozygosity }\left(\mathrm{H}_{\mathrm{e}}\right)\end{array}$ & $\begin{array}{c}\text { Inbreeding } \\
\text { coefficient }(\mathrm{IC})^{\mathrm{z}} \\
\end{array}$ \\
\hline UDP96-001 & 6 & 2.25 & 1.13 & 0.24 & 0.56 & 0.57 \\
\hline UDP96-003 & 6 & 3.3 & 1.39 & 0.18 & 0.7 & 0.74 \\
\hline UDP96-008 & 3 & 1.54 & 0.65 & 0.16 & 0.35 & 0.55 \\
\hline UDP96-010 & 3 & 1.52 & 0.59 & 0 & 0.34 & 1 \\
\hline UDP96-013 & 6 & 2.57 & 1.27 & 0.25 & 0.61 & 0.59 \\
\hline UDP96-019 & 4 & 2.29 & 0.96 & 0.58 & 0.56 & -0.03 \\
\hline UDP97-401 & 7 & 2.66 & 1.21 & 0.24 & 0.62 & 0.62 \\
\hline UDP97-402 & 5 & 1.92 & 0.91 & 0.26 & 0.48 & 0.45 \\
\hline UDP97-403 & 5 & 2.18 & 1.08 & 0.13 & 0.54 & 0.76 \\
\hline UDP98-405 & 2 & 1.11 & 0.21 & 0 & 0.1 & 1.0 \\
\hline UDP98-407 & 8 & 4.46 & 1.69 & 0.27 & 0.78 & 0.65 \\
\hline
\end{tabular}

${ }^{\mathrm{z}}$ Definition of inbreeding coefficient according to Wright (1965).

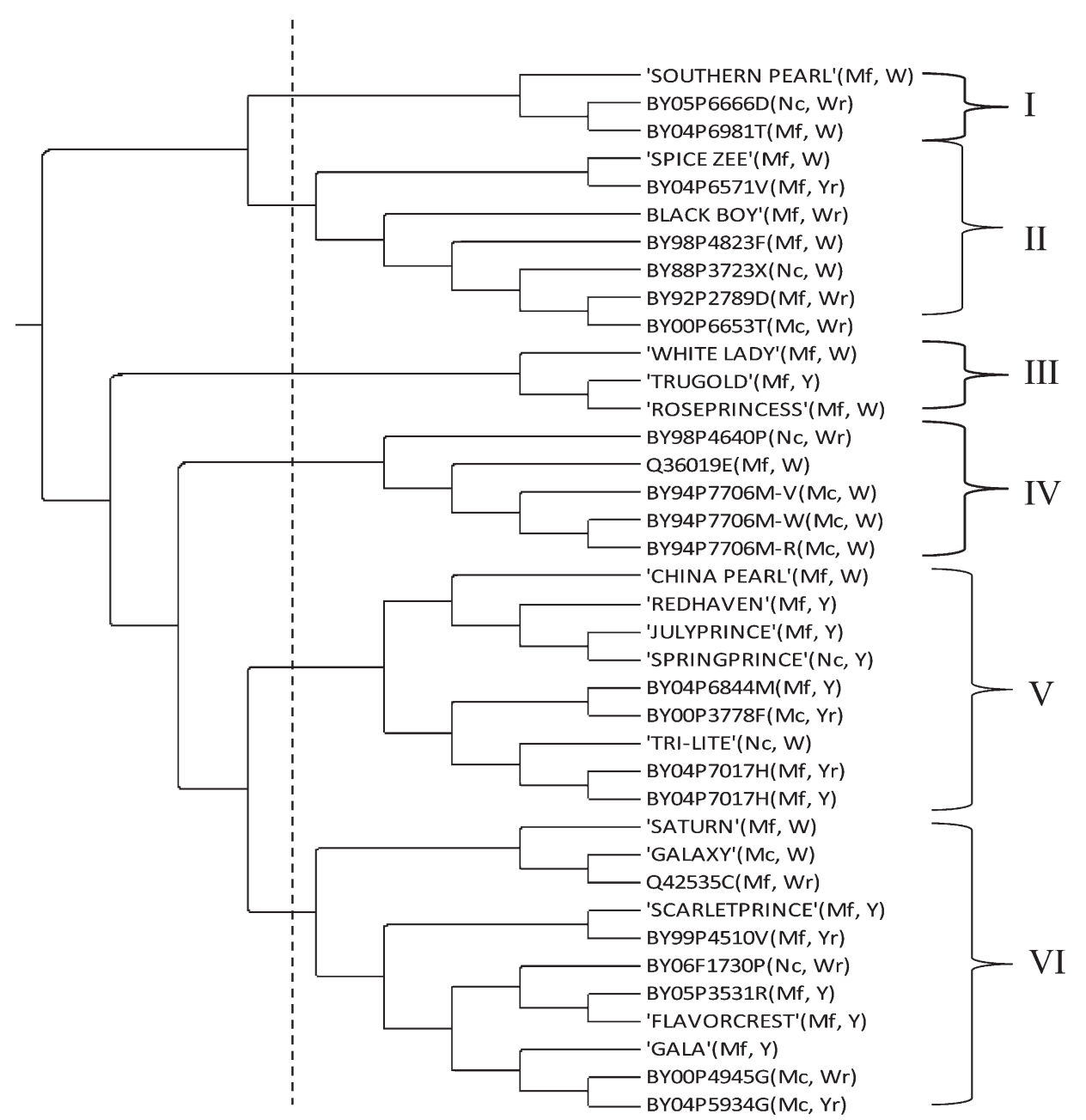

Fig. 1. Neighbor-joining dendrogram depicting the relationships among the 37 peach accessions (Table 1) from USDA-ARS, Byron, GA. Kinship coefficient (Cockerham and Weir, 1987) was used as a measure of genetic distance. $\mathrm{M}=$ melting; $\mathrm{N}=$ non-melting; $\mathrm{c}=$ clingstone; $\mathrm{f}=$ freestone; $\mathrm{r}=$ red flesh; $\mathrm{w}=$ white flesh; $\mathrm{y}=$ yellow flesh.
Two other cultivars with Asian parentage ('China Pearl' and 'Julyprince') grouped closely in Cluster $\mathrm{V}$ indicating common ancestry as well. Of the 37 accessions tested, a majority (20) were grouped in Clusters V and VI. 'Redhaven', a parent of 'TruGold' grouped in Cluster V, and the flat-shaped 'Saturn' and 'Galaxy', which probably share ancestors from China through eastern Europe, grouped closely together in Group VI. In addition, BY00P4945g (a parent of BY04P5934g) grouped together in Cluster VI.

Clustering of accessions based on flesh type showed that melting and non-melting types were interspersed among six clusters with the exception of those in Cluster III, in which all three accessions were melting freestone peaches. A similar trend was observed in the distribution of white and yellow-fleshed accessions with the exception of Cluster IV, in which all were white-fleshed. Most of the redfleshed accessions grouped in Clusters II and VI. Although 'Blackboy' (from New Zealand but of unknown origin) along with selections from Byron, GA (BY04P6571v, BY92P2789d, and BY00P6653t) grouped in Cluster II, Q42535c (which originated from France) along with Byron, GA, selections BY 99P 4510v, BY06F 1730p, BY00P4945g, and BY04P5934g 

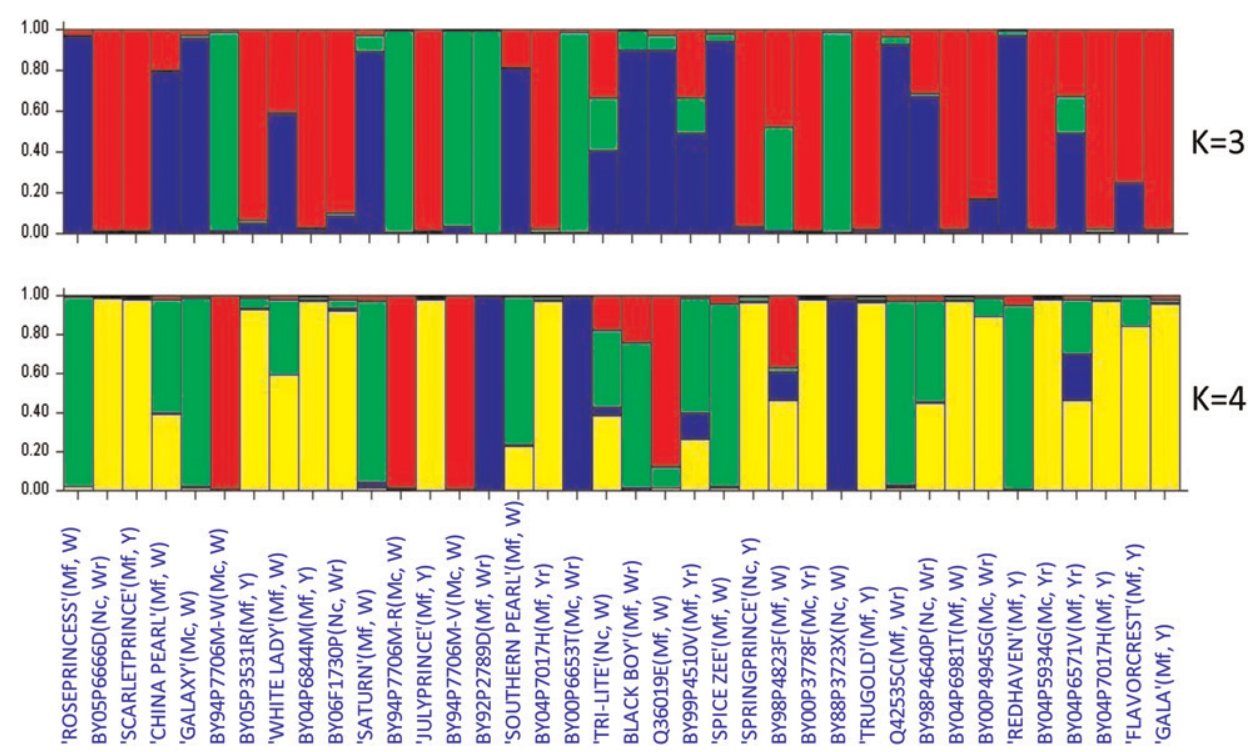

Fig. 2. Inferred population stratification among 37 Prunus persica accessions (Table 1) from a microsatellite data set of 15 primers based on STRUCTURE output. Model-based clustering algorithm (Pritchard et al., 2000) was applied to simple sequence repeat (SSR) data. The most probable clusters were obtained at $\mathrm{K}=3$ and $\mathrm{K}=4$, where $\mathrm{K}$ is the potential number of clusters that may exist in the overall sample. Each vertical line represents one individual multilocus genotype and each color represents the most likely ancestry of the cluster from which the genotype or partial genotype was derived. Individuals with multiple colors have admixed genotypes from different clusters. $\mathrm{M}=$ melting; $\mathrm{N}=$ non-melting; $\mathrm{c}=$ clingstone; $\mathrm{f}=$ freestone; $\mathrm{r}=$ red flesh; $\mathrm{w}=$ white flesh; $\mathrm{y}=$ yellow flesh.

grouped in Cluster V1. These results suggest that there are several distinct sources of the red-fleshed trait. Because the redfleshed trait has existed primarily in heirloom peaches in France and later in North America, it was not possible to trace their origins with certainty.

Evaluation for population stratification using model-based Bayesian cluster analysis partitioned the 37 accessions into four groups (Fig. 2) and was partly compatible with the dendrogram based on kinship coefficient. Most accessions that clustered together in the dendrogram tended to cluster in the same group. To view the change of partitioned groups at lower $\mathrm{K}$, we have also included the results of $\mathrm{K}=3$ in Figure 2. The pattern of partitioning was highly consistent at $\mathrm{K}=3$ and $\mathrm{K}=4$. The minor change observed at $\mathrm{K}=4$ was that accessions BY00P6653t, BY92P2789d, and BY88P3723x were separated as a new cluster. These three accessions are related in that they have local heirloom cultivars in their parentage. The extent of admixture in each individual accession was well illuminated in this cluster analysis. Accessions 'China Pearl', 'White Lady', and BY98P4640p are all hybrids between two different clusters, whereas 'Tri-Lite', BY984823f, and BY00P1510v have parentage contribution from three different clusters. Ornamental cultivars with Japanese parentage grouped together in a separate cluster (blue) and the commercial types of unclear affinity clustered together (yellow and green) (Fig. 2).

Parentage and Sibship analysis. Of the 37 accessions tested, two pairs of parent-offspring (maternity or paternity) relationships were identified at $95 \%$ confidence level using parentage analysis (Table 5). The first pair ('Julyprince' vs. 'Springprince') did not appear to be related based on published pedigrees. However, the second pair (BY00P6653t vs. BY92P2789d) has a common but not immediate ancestor, and this relationship was established (Table 5). 'Red English' is the common ancestor of these two accessions. Similarly, BY00P3778f and BY04P6844m share a common ancestor ('O'Henry') but are not full sibs. The relationship of BY00P4945g as a parent of BY04P5934g was also established, although neither is related to 'GaLa'. The result of sibship reconstruction by COLONY is presented in Table 5 . With all the generated putative siblings in three repeated runs, only those that had a probability above 0.95 were retained. This conservative approach resulted in two full-sib families involving five accessions; however, the analysis did not result in half-sib families at the probability level tested (above $0.95 \%$ confidence). No relationship was identified at a positive LOD value for these accessions. The identified putative parent-offspring and full-sib relationships were highly compatible with the kinship-based cluster analysis (Fig. 1). Each of the identified family members was closely grouped together in the neighbor-joining tree based on SSRs (Fig. 2), although these did not fit well with a putative genetic relationship as determined by their recorded pedigree. Some of the expected parentage relationships such as for descendents of 'Blazeprince' were not significant.

IDENTIFICATION OF DUPLICATE GENOTYPES. Pairwise comparisons of the peach cultivars based on multilocus SSRs revealed two sets of synonymous groups among the 37 accessions. The first synonymous group confirmed that duplicate samples of BY04P7017h were the same genotype. The second group comprised three BY94P7706m clones, which exhibited white, red, or variegated flowers but on the same tree, thus having the identical genetic background. However, the mutation that

Table 5. Likelihood assignment for parentage and sibship relationships among 37 peach accessions from the germplasm collection of USDAARS at Byron, GA, based on 15 simple sequence repeat markers.

\begin{tabular}{lllll}
\hline Accession 1 & Accession 2 & Accession 3 & \multicolumn{1}{c}{ Relationship } & \multicolumn{1}{c}{ Common parent } \\
'Springprince' & 'Julyprince' & & Parent-offspring & None \\
BY00P6653t & BY92P2789d & & Parent-offspring & 'Red English' \\
BY04P6844m & BY00P3778f & & Full sibling & 'O'Henry' \\
BY00P4945g & BY04P5934g & 'GaLa'y & Full sibling & BY96P5245 $\times$ BY96P4554
\end{tabular}

${ }^{\mathrm{z}}$ Critical likelihood ratio in terms of the natural logarithm for assignment of parentage are 4.75 at greater than $95 \%$ confidence.

${ }^{\mathrm{y}} \mathrm{Common}$ parent has not been reported for 'GaLa'. 
resulted in changes in the anthocyanin pathway among the three BY94P7706m clones could not be detected with the SSR markers.

Cross-species AMPlification. Of the 15 SSR markers tested, 14 were capable of amplifying DNA in all nine different Prunus species tested. DNA amplification was considered to be successful when sharp bands corresponding to the expected size range were observed on agarose gels (data not shown). All 14 primers were polymorphic and generated multiple alleles. The primer sequence designed for the microsatellite flanking regions at locus UDP96-003 did not uniformly amplify DNA in all Prunus species from other hosts, whereas DNA of all true peach accessions ( $P$. persica) were amplified. Eleven of the 14 primers produced amplification profiles in the expected allele range, whereas three (UDP96-001, UDP96013, and UDP97401) amplified DNA, but the allele peaks detected were out of range as a result of heterologous amplifications in the primerbinding regions of these species.

\section{Discussion}

SSR markers in Prunus species have been widely used for cultivar identification, genetic mapping, and phylogenetic analyses (Aranzana et al., 2003; Testolin et al., 2000). One of the major criteria in cultivar identification using molecular markers is to select polymorphic loci that can unambiguously match the DNA profiles of tested individuals. In this study, the efficacy of a small set of SSR loci in establishing multilocus profiles and genotype matching was tested in peach germplasm commonly used in the breeding program.

High levels of expected heterozygosity $\left(\mathrm{H}_{\mathrm{e}}=0.54\right)$ was observed among the peach accessions tested; however, the average observed heterozygosity was only 0.22 . A relatively large discrepancy between $\mathrm{H}_{\mathrm{e}}$ and $\mathrm{H}_{\mathrm{o}}$ indicates high inbreeding among the U.S. peach germplasm. These results, together with the large inbreeding coefficient (0.62), are in accordance with that of Bouhadida et al. (2011) in which 15 SSRs used on a set of 212 cultivars originating in or introduced to Spain revealed an observed mean heterozygosity value of 0.23 . On the other hand, a similar study on 50 peach and nectarine ( $P$. persica var. laevis) cultivars has revealed higher observed heterozygosity of 0.47 (Testolin et al., 2000). This higher observed heterozygosity could be attributed to the diverse samples that were tested in their study. Analyzed germplasm included rootstocks, ornamental types, high- and low-chill germplasm, and cultivars from different geographical origins.

Clustering of accessions based on kinship coefficient indicated genetic relationships among accessions that originated from various geographical regions and breeding lines developed for genetic improvement. Accessions that were of U.S. origin grouped in the third cluster, whereas those with Asian parentage grouped in Cluster IV. 'Spice Zee' (Cluster II) and 'Tri-Lite' (Cluster V), which are reported to have a plum parent, grouped together with the peach accessions. Amplification profiles with the 15 primers and cluster analysis suggest that these accessions may be pure peach; tree and fruit characteristics support this hypothesis. Similarly, molecular and morphological evidence suggests BY98P4823f is a self, not a hybrid, perhaps as a result of incompatible or non-viable pollen of $P$. triloba used in the hybridization.

Identification of duplicate samples and clones from a single tree were possible using the 15 SSR markers. Cluster analysis confirmed that duplicate samples of BY04P7017h were the same genotype. In addition, the three clones exhibiting white, red, or variegated flowers had identical genetic backgrounds. We infer that a mutation in the anthocyanin pathway among the three BY94P7706m clones could have resulted in the variegation; however, this could not be detected with the SSR markers. The anthocyanin biosynthesis pathway in the Rosaceae is controlled by differential regulation of MyB transcription factors (Wang et al., 2010). The possible reason for differential anthocyanin expression in these clones is unknown. SSR markers specific for regulatory genes in the anthocyanin pathway need to be designed to detect possible mutations and/or gene coding sequences responsible for differential color expression. It also needs to be pointed out that the clustering analysis used kinship coefficient as genetic distance $(\mathrm{G})$, which is the probability that two genes taken at random from a given locus are identical by descent (Cockerham and Weir, 1987). In this study, the SSRs used for cultivar identification were sufficient for matching individual genotypes.

Inferred population stratification using STRUCTURE analysis showed cultivars and breeding lines clustering together (Fig. 2). This is not surprising because several accessions were derived from the same breeding program. The distribution of melting and non-melting cultivars indicates the presence of a common genetic base among these accessions and perhaps the lack of use of canning type peaches as a source of the nonmelting trait. In the Bayesian clustering model, white-fleshed accessions BY00P6653t, BY92P2789d, and BY88P3723x clustered together indicating the effectiveness of these SSR markers. Although several meaningful results were produced, certain questions were raised as well. 'TruGold' was previously described as a doubled haploid genotype (Finn and Clark, 2008), in which case it should be homozygous for all loci. However, our results indicated this accession to be homozygous for only 13 of the 15 loci tested. Several reruns of PCR amplifications with the original DNA and newly extracted DNA produced the same results. We are currently in the process of genotyping every single tree of this accession to verify the genetic identity of all the germplasm accessions.

Although likelihood assignment identified paternity and sibship relationships among the accessions tested, cluster analysis produced several meaningful groupings based on pedigree analysis as well. The positioning of the pair BY00P6653t and BY92P2789d established the parent-offspring claim that these have 'Red English' as a common ancestor (Table 5). However, not all purported parent-sibship relationships could be determined using the SSRs. An unanswered question raised by the analysis concerns 'TruGold' and 'Redhaven' in which information on published pedigrees was not consistent with our results. This is not surprising, and such differences in identification of sibship relationships have been reported, in which the official pedigree could not be confirmed (Testolin et al., 2000). In a similar study on pedigree analysis of peach cultivars in which the information of at least one parent was available, inconsistencies were recorded with the pedigree data of 11 of 38 cases (Aranzana et al., 2003).

To use markers universally in breeding programs, it is important that they are transferable to related species. Because chromosome segments are conserved in many species, these markers could be valuable in comparative genomic studies. A primer set to detect inter- and intraspecific variation is beneficial because it reduces effort required for primer development. 
In our study, 11 of the 15 SSR markers (73.3\%) provided accurate cross-amplification and were polymorphic in related Prunus species tested. Similar results have been reported by other researchers in which SSR markers were cross-transferable to a certain extent in almond $(P$. dulcis), apricot, japanese plum, european plum, sweet cherry $(P$. avium $)$, and sour cherry $(P$. cerasus) (Cipriani et al., 1999; Wünsch and Hormaza, 2002). Although a $100 \%$ success rate in cross-amplification of related species has not been reported, the broad cross-species transportability in other stone fruit crops makes these markers valuable in characterization of these genomes. Categorization of scions and stocks of related species is useful in organizing germplasm collections and in commercial sectors such as nurseries where fruit trees are vegetatively propagated.

In conclusion, SSRs used in this study were highly informative in identifying peach accessions and breeding lines. Pedigree structure among accessions developed at SEFTNRL could be inferred based on the multilocus data and duplicated accessions readily identified with high statistic rigor. However, we need to keep in mind that in several fruit species, somatic mutations of traits ("sports") have been reported and this could contribute to discrepancies. The original and derived cultivars could be identical at the genetic level except for the mutation, which could be responsible for the difference. Mutations in the variegated genotypes were identified phenotypically based on flower color and complemented by SSR markers. Cultivar identification, parentage and sibship analysis, and assessment of diversity are useful for peach germplasm management and breeding, especially with increasing constraints in peach production in the United States. The SSR markers validated in this study will serve as a valuable resource in peach breeding programs.

\section{Literature Cited}

Aranzana, M.J., J. Garcia-Mas, J. Carbó, and P. Arús. 2002. Development and variability analysis of microsatellite markers in peach. Plant Breed. 121:87-92.

Aranzana, M.J., J. Carbó, and P. Arús. 2003. Microsatellite variability in peach [Prunus persica (L.) Batsch]: Cultivar identification; marker mutation; pedigree inferences and population structure. Theor. Appl. Genet. 106:1341-1352.

Bouhadida, M., M.A. Moreno, M.J. Gonzalo, J.M. Alonso, and Y. Gogorcena. 2011. Genetic variability of introduced and local Spanish peach cultivars determined by SSR markers. Tree Genet. Genomes 7:257-270.

Brovelli, A.E., J.K. Brecht, W.B. Sherman, and C.A. Sims. 1998. Quality of fresh-market melting and nonmelting flesh genotypes as affected by post-harvest chilling. J. Food Sci. 63:730-733.

Byrne, D.H. 1999. Founding clones of low-chill fresh market peach germplasm. Fruit Var. J. 53:162-171.

Cipriani, G., G. Lot, W.G. Huang, M.T. Marrazzo, E. Peterlunger, and R. Testolin. 1999. AC/GT and AG/CT microsatellite repeats in peach [Prunus persica (L.) Batsch]: Isolation, characterization and cross-species amplification in Prunus. Theor. Appl. Genet. 99:65-72. Cockerham, C.C. and B.S. Weir. 1987. Correlations, descent measures: Drift with migration and mutation. Proc. Natl. Acad. Sci. USA 84:8512-8514.

Dieringer, D. and C. Schlötterer. 2002. Microsatellite analyser (MSA): A platform independent analysis tool for large microsatellite data sets. Mol. Ecol. Notes 3:167-169.

Dirlewanger, E., P. Cosson, M. Tavaud, M.J. Aranzana, C. Poizat, A. Zanetto, P. Arús, and F. Laigret. 2002. Development of microsatellite markers in peach [Prunus persica (L.) Batsch] and their use in genetic diversity analysis in peach and sweet cherry (Prunus avium L.). Theor. Appl. Genet. 105:127-138.
Downey, S.L. and A.F. Iezzoni. 2000. Polymorphic DNA markers in black cherry (Prunus serotina) are identified using sequences from sweet cherry, peach and sour cherry. J. Amer. Soc. Hort. Sci. 125: 76-80.

Evanno, G., S. Regnaut, and J. Goudet. 2005. Detecting the number of clusters of individuals using the software STRUCTURE: A simulation study. Mol. Ecol. 14:2611-2620.

Felsenstein, J. 1989. PHYLIP-Phylogeny Inference Package (version 3.2). Cladistics 5:164-166.

Fideghelli, C., G.S. Della, F. Grassi, and G. Morric. 1998. The peach industry in the world: Present situation and trend. Acta Hort. 465:29-40.

Finn, C.E. and J.R. Clark. 2008. Register of new fruit and nut varieties-List 44. HortScience 43:1321-1343.

Jones, O.R. and J. Wang. 2010. Colony: A program for parentage and sibship inference from multilocus genotype data. Mol. Ecol. Res. 10: 551-555.

Kalinowski, S.T., M.A. Sawaya, and M.L. Taper. 2006. Individual identification and distributions of genotypic differences between individuals. J. Wildl. Mgt. 70:1148-1150.

Liu, J. and S. Muse. 2005. PowerMarker: An integrated analysis environment for genetic marker analysis. Bioinformatics Application Note 21:2128-2129.

Marshall, T.C., J. Slate, L.E.B. Kruuk, and J.M. Pemberton. 1998. Statistical confidence for likelihood-based paternity inference in natural populations. Mol. Ecol. 7:639-655.

Morgante, M. and A.M. Olivieri. 1993. PCR-amplified microsatellites as markers in plant genetics. Plant J. 3:175-182.

Okie, W.R. 1998. Handbook of peach and nectarine varieties. U.S. Dept. Agr., Agr. Res. Serv., Agr. Hdbk. 714.

Page, R.D.M. 1996. An application to display phylogenetic trees on personal computers. CABIOS 12:357-358.

Peakall, R. and P.E. Smouse. 2006. Genalex 6: Genetic analysis in Excel. Population genetic software for teaching and research. Mol. Ecol. Notes 6:288-295.

Powell, W., M. Morgante, C. Andre, M. Hanafey, J. Vogel, S. Tingey, and A. Rafalski. 1996. The comparison of RFLP, RAPD, AFLP and SSR (microsatellite) markers for germplasm analysis. Mol. Breed. 2:225-238.

Pritchard, J.K., M. Stephens, and P. Donnelly. 2000. Inference of population structure using multilocus genotype data. Genetics 155:945-959. Ramakrishna, W., K.V. Chowdari, M.D. Lagu, V.S. Gupta, and P.K. Ranjekar. 1995. DNA fingerprinting to detect genetic variation in rice using hypervariable DNA sequences. Theor. Appl. Genet. 90:1000-1006.

Saitou, N. and M. Nei. 1987. The neighbor-joining method: A new method for reconstructing phylogenetic trees. Mol. Biol. Evol. 4:406-425.

Scorza, R., S.A. Mehlenbacher, and G.W. Lightner. 1985. Inbreeding and coancestry of freestone peach cultivars of the eastern United States and implications for peach germplasm improvement. J. Amer. Soc. Hort. Sci. 110:547-552.

Scorza, R. and W.R. Okie. 1990. Peaches (Prunus), p. 177-231. In: Moore, J.N. and J.R. Ballington (eds.). Genetic resources of temperate fruit and nut crops. Intl. Soc. Hort. Sci., Wageningen, The Netherlands. Testolin, R., T. Marrazzo, G. Cipriani, R. Quarta, I. Verde, M.T. Dettori, M. Pancaldi, and S. Sansavini. 2000. Microsatellite DNA in peach [Prunus persica (L.) Batsch] and its use in fingerprinting and testing the genetic origin of cultivars. Genome 43:512-520.

Waits, L.P., G. Luikart, and P. Taberlet. 2001. Estimating the probability of identity among genotypes in natural populations: Cautions and guidelines. Mol. Ecol. 10:249-256.

Wang, K.L., K. Bolitho, K. Grafton, A. Karunairetnam, T.K. McGhie, R.V. Espley, R.P. Hellens, and A.C. Allan. 2010. An R2R3 MYV transcription factor associated with regulation of the anthocyanin biosynthetic pathway in Rosaceae. BMC Plant Biol. 10:50-67.

Wünsch, A. and J.I. Hormaza. 2002. Molecular characterisation of sweet cherry (Prunus avium L.) genotypes using peach [Prunus persica (L.) Batsch] SSR sequences. Heredity 89:56-63.

Wright, S. 1965. The interpretation of population structure by F-statistics with special regard to systems of mating. Evolution 19:395-420. 